\title{
Urdimento
}

Revista de Estudos em Artes Cênicas

E-ISSN: 2358.6958

\section{Dança em texto: comunicação através dos textos sobre a dança}

\author{
Henrique Rochelle
}

\section{Para citar este artigo:}

ROCHELLE, Henrique. Dança em texto: comunicação através dos textos sobre a dança. Urdimento, Florianópolis, v. 2, n. 38, ago./set. 2020.

DOI: http:/dx.doi.org/10.5965/14145731023820200034

Este artigo passou pelo Plagiarism Detection Software | iThenticate 


\title{
Dança em texto: comunicação através dos textos sobre a dança
}

\author{
Henrique Rochelle ${ }^{2}$
}

\begin{abstract}
Resumo
Formas textuais de abordagem da dança cênica ocidental são aqui consideradas através de uma proposta de divisão em quatro grupos: manuais, teoria, história, e crítica. Nelas, busca-se como baliza a ideia de que a dança é linguagem: uma forma de comunicação organizada por um sistema próprio, que é elaborado e explorado de modo particular por cada tipo de texto. Esta investigação se dirige a questionamentos como o porquê escrevemos sobre dança e o quê se escreve sobre dança, discutindo a especificidade dos escritos, sua relevância, e suas formas de apresentar e desenvolver elementos fundamentais da comunicação da dança.
\end{abstract}

Palavras-Chave: Dança. Comunicação. Texto. Textos sobre dança. Escrita.

\section{Dance in writing: communication in writings about dance}

\begin{abstract}
Written approaches to western performing dance are here considered in a proposal for a division into four groups: manuals, theory, history, and criticism. A key concern in dealing with them is the idea that dance is a language: a kind of communication organized in its own system, that is elaborated and explored in a particular way by each kind of writing. This investigation addresses questions such as why we would write about dance, and what we would write about dance, by discussing the specificity of dance writings, their relevance, and forms of presenting and developing fundamental elements of dance communication.
\end{abstract}

Keywords: Dance. Communication. Text dance texts. Writing.

1 Versões anteriores deste texto foram apresentadas, primeiro sob o título "Communication through dance writings: manuals, history, theory, and criticism”, em capítulo do livro Interdisciplinarity and the Performing Arts: Contemporary Perspectives, publicado pela Malta University Press em Msida, 2018; e também como o capítulo "A Crítica e Outras Escritas Sobre a Dança", parte da Tese de Doutorado A Crítica Como Metodologia e Análise da Recepção na Dança, defendida no PPG Artes da Cena da Universidade Estadual de Campinas (Unicamp). Seus conteúdos, aqui apresentados em versão revista (e ampliada e traduzida), refletem resultados de pesquisas realizadas através do financiamento de duas bolsas de Doutorado pela FAPESP, e uma bolsa de Pós-Doutorado pelo CNPq.

2 Professor Colaborador da Escola de Comunicações e Artes da USP, Doutor e Mestre em Artes da Cena (Unicamp / Paris 8), Especialista em Mídia, Informação e Cultura (USP), Bacharel em Estudos Literários (Unicamp), critico de dança (APCA), editor dos sites Da Quarta Parede e Criticatividade. rochelle.hra@gmail.com 
As reflexões textuais sobre a dança remontam à origem remota da dança cênica, englobando os tratados e as formas de registro do movimento, a sistematização do seu ensino, e, posteriormente, a apreciação da produção artística, e a reflexão teórica acerca desse domínio do conhecimento. Seus propósitos não se limitam a transcrever a dança: não se tratam de discursos que intentam uma substituição, mas sim um alargamento, permitindo ao campo da dança uma expansão, nesse caso, para o formato textual.

O que aqui se propõe é que a escrita pode ser uma forma de discussão da recepção da dança, através de múltiplas e específicas formas de trabalho, aqui discutidas com o objetivo de estabelecer uma distinção qualitativa entre essas formas e suas possibilidades.

A necessidade de se discutir o espectro de produção textual em dança vem de uma observação de prática pedagógica que nota que o trabalho técnico da formação do intérprete de dança se encontra pouco acompanhado de reflexões teóricas, ou mesmo históricas. Considera-se aqui, um efeito do contexto brasileiro de ensino da dança, que permite que um indivíduo abra uma escola e ensine a dança que quiser, da maneira que considerar apropriada, para aqueles que se dispuserem a pagar por isso. Isso aumenta não apenas a inconstância, mas sobretudo as possibilidades de background de formação dos bailarinos, que, frequentemente ultrapassando apenas um tipo de aula técnica, costumam experimentar diversos estilos e modalidades, criando um repertório misturado a partir das ofertas de suas academias e locais de origem. Esse repertório, que passa pelo balé, pela dança moderna e pelo contemporâneo (em suas muitas possibilidades de abordagem e referências), e também pelas danças de rua, do hip-hop, sapateado, danças de salão, dança do ventre, entre outras, chega inclusive a outras áreas, não exatamente da dança, mas que naquelas mesmas instituições se apresentam, às vezes em paridade, como exercícios de circo, acrobacias, ginástica artística e rítmica, além de todas as possibilidades de contato e experiência em danças sociais e populares.

Esse vasto catálogo de experiência prévia não costuma incluir relações com os escritos sobre a dança, que parecem legados a um segundo plano. A percepção 
desse segundo plano sugere questionamentos maiores, até mesmo acerca da existência de tais fontes, nem sempre conhecidas daqueles que trabalham e produzem dança. Surge aqui, uma pergunta em dois tempos, que origina o questionamento deste capítulo: O que se escreveria sobre a dança? E por quê se escreveria sobre a dança?

Para discutir esse questionamento, aqui apresenta-se uma breve abordagem histórica aos escritos sobre a dança, numa proposta de passar em vistoria sobre alguns dos diferentes tipos de texto que se produzem sobre essa arte. Analisando as suas similaridades e diferenças, e sua articulação, apresenta-se, não apenas um relato acerca do que foi escrito sobre a dança, mas também sobre o por quê esses escritos são relevantes, e o como essas formas de escrita, cada uma a sua maneira específica, têm acompanhado o desenvolvimento da dança e alargado o entendimento que têm pesquisadores, acadêmicos e praticantes acerca daquela arte.

\section{Múltiplas Escritas sobre a Dança}

Abordagens escritas da dança cênica podem ser encontradas desde o século XVI. Em 1589, o clérigo francês Jehan Tabourot publicou Orchésographie:Traité en forme de dialogue, par lequel toutes personnes peuvent facilement apprendre \& practiquer l'honneste exercice des dances (Orquesografia e Tratado em forma de diálogo, pelo qual todas as pessoas podem facilmente aprender e praticar o exercício honesto da dança), sob o pseudônimo de Thoinot Arbeau. Esse livro apresenta uma reflexão acerca das danças de corte de seu tempo, incluindo informações detalhadas dos passos de dança e entalhes dos posicionamentos, indicando como deveriam ser executados pelos bailarinos.

Essas danças de corte foram predecessoras dos balés de corte, e o interesse em registrá-las em forma de livro - em um momento em que a criação e produção de livros não era uma atividade nem simples nem barata - é por si só uma indicação da relevância dos escritos de dança para aquela sociedade (sobre a manutenção desse interesse e dos processos de reflexão acerca da dança em 
escritos numa sociedade mais próxima do nosso tempo, ver Croce, 1978). A obra de Arbeau mostra um intento em preservar a dança em formatos que sejam mais acessíveis e que viajem mais facilmente, tais como os livros. É pela reflexão sobre essa possibilidade, bem como sobre outros possíveis interesses em se escrever sobre a dança, que a pesquisa aqui apresentada partiu de uma categorização das diversas formas de escrito possíveis, quatro delas sendo elencadas para desenvolver a reflexão aqui proposta.

Claramente, a categorização que aqui se apresenta não responde por todas as possibilidades de escrita sobre a dança, e revela o interesse acadêmico pontual deste texto. Por exemplo, de início, materiais promocionais foram excluídos da análise, tais como os sites de companhias de dança, e propagandas de turnês e apresentações. Também, por questões de fiabilidade, relatos e testemunhos focados em experiências pessoais, como cartas e diários, não foram considerados.

Ainda que esses relatos pessoais ofereçam profunda informação acerca das práticas da dança, eles dificilmente podem ser considerados de um ponto de vista factual, como reportando algo além das próprias experiências de seus autores. Mesmo que eles sejam fundamentais para diversas formas de estudo da dança (cf. Launay, 2011; Layson, 1998), eles precisam ser considerados com cuidado e distanciamento crítico, uma vez que raramente carregam o interesse de registrar algo para além da percepção do próprio autor, tendo muito dificilmente sido preparados para a disponibilização ao público geral, e facilmente arriscando operar como o que Pavis (2008) chama de filtros deformantes na análise e discussão das obras.

Essa suspeita de relatos pessoais pelo ponto de vista acadêmico e historiográfico pode ser exemplificada pela análise que Modris Eksteins apresenta em seu livro Rites of Spring: The Great War and the Birth of Modern Age (2000), quando, ao tratar de eventos da temporada de estreia da Sagração da Primavera (Paris, 1913) de Nijinsky, menciona alguns relatos da primeira apresentação pública da obra, como o de Gertrude Stein, por exemplo. Eksteins propõe que os eventos daquela noite foram tão relevantes, que muitas pessoas se sentiram neles incluídas, mesmo que não estivessem de fato presentes na apresentação. 
Comparando as observações de distintos indivíduos, o historiador aponta que diversos dos relatos, que são frequentemente tidos como descrições de primeiramão da estreia da Sagração, registrados em diários e cartas, na verdade eram ficções. Foram registrados em texto, mas por pessoas que não estavam de fato presentes na tumultuosa estreia.

A memória, enquanto "processo de ressignificação elaborado a partir de percepções e questionamentos feitos no presente" (Cerbino, 2009, p. 33), nem sempre é uma fonte de precisão histórica (ver Navas, 2015, sobre os usos de fontes primárias na pesquisa em dança). Isso não é um problema em si, é uma característica desses materiais, que intencionavam registrar a experiência para os próprios autores e para as pessoas a quem eles estivessem escrevendo, não se destinando inicialmente a reflexões acadêmicas. Essa reflexão acerca da aplicação possível das fontes em estudos de história da dança se tornou um critério principal para o crivo da coleção de exemplos que aqui se discutem, e sua consequente organização em diferentes categorias.

A partir da consideração dos exemplos tidos como pertinentes, as categorias que aqui se discutem são quatro: Manuais de Dança, Crítica de Dança, História da Dança, e Teoria da Dança. Manuais é a categoria das formas de escrita que focam na instrução de como dançar; a Crítica inclui textos focados na apreciação e na avaliação de obras de arte; História apresenta os relatos sobre eventos e indivíduos, e suas relevâncias para a continuidade e transformação dessa forma de arte; e Teoria, a mais larga das categorias, inclui estudos e análises de dança (dança, como em 'esta forma artística', e não 'danças' como em 'as coreografias ou os estilos de dança').

Essas diferente categorias têm um elemento fundamental em comum: a ideia de que a dança funciona como uma linguagem (cf. Rochelle, 2013; 2015; 2017), a partir, sobretudo, dos pontos expressos por Roland Barthes $(1964,1995,2004)$ e Roman Jakobson (1971), que apresentam aplicações e funções da linguagem para além de suas características formais. Assim apresentando o entendimento expandido do termo que, centrado na possibilidade comunicativa das linguagens, 
propõe que a dança seja uma linguagem por ser sistematicamente organizada para comunicação.

Esse conceito de que existe uma associação direta entre a dança e a comunicação foi validado pelos exemplos considerados nas quatro formas de texto aqui pontuadas, e nenhum exemplo de crítica, teoria, história ou manual que desconsiderasse o aspecto comunicativo da dança pôde ser encontrado. Os textos de crítica se mostram principalmente dedicados a tratar de quão bem uma obra / ou um bailarino / ou um coreógrafo é capaz de comunicar algo ao público, através da dança. Todas as alterações históricas nos estilos de dança podem ser observadas como ligadas à necessidade de mudança das formas criadas para que elas melhor se relacionem a um contexto ou ideia - ou seja, elas acontecem em e por um propósito comunicativo. Se não houvesse comunicação pela dança, se ela não fosse capaz de significar algo para alguém, não seria possível analisar, discutir, teorizar sobre ela - posto que esses também são processos orientados para o outro, e não unicamente auto-referenciais. Finalmente, se não houvesse comunicação de uma pessoa a outra na dança, não seria pertinente se preocupar com os modos como ela deve ser executada, o que responde pelos manuais de dança.

Com essa consideração, investigar as escritas sobre a dança se torna uma forma de investigar como esses escritos apresentam aspectos da comunicação da dança enquanto linguagem, o que eles fazem em modos e intenções diferentes. É essa possibilidade analítica que é usada como a baliza metodológica deste artigo, refletindo, para cada uma das formas de escrita que são discutidas, a forma como ela organiza sistemas e comunicação entre artistas e públicos. Ao final, uma conclusão reflete acerca dessas quatro formas de escrita comparativamente, indicando características que são observadas individualmente em cada forma de texto, podendo ser identificadas como elementos característicos, isolados de uma forma específica, e quais aspectos podem ser vistos como mais gerais, elementos interdisciplinares do todo considerado de escritas sobre a dança. 


\section{Os Manuais de Dança: informação para a formação}

Oferecendo informação técnica sobre o treinamento, a preparação, a educação e a formação dos bailarinos, os manuais de dança normalmente focam na apresentação de sistemas fechados de comunicação através da dança, direcionando-se ao desenvolvimento e aperfeiçoamento das habilidades e capacidades dos bailarinos, dentro desses sistemas, de suas estruturas e propostas e objetivos específicos. Os trabalhos mais antigos dessa natureza frequentemente apresentam ideias rígidas de como seria a execução apropriada de um movimento, sua colocação otimizada em coreografias, e os métodos para sua realização. Esses sistemas podem ser considerados como fechados: os manuais oferecem opiniões nas melhores formas (e nas formas adequadas) de se realizar e usar a dança segundo aquilo que idealizam seus sistematizadores.

Isso responde pela grande variedade e distinção entre esses sistemas. Movimentos são descritos diferentemente, executados diferentemente e com intenções diferentes, que refletem os objetivos, as propostas e opiniões dos indivíduos responsáveis tanto pelos manuais como pelas tradições em dança que eles representam. No Orchésographie, por exemplo, Arbeau (1589) ensina aos dançarinos como eles devem posicionar seus corpos e executar os movimentos, de acordo com os princípios de moralidade e decoro daquele tempo, bem como considerando as roupas da época, posto que, naquele momento, ele escrevia sobre as danças sociais realizadas na corte, em sua maioria dentro de ocasiões de festividades e eventos.

Tradições clássicas também foram registradas em manuais, como o Basic Principles of Classical Ballet, de Agrippina Vaganova (1946), até hoje usado pelo mundo como uma possibilidade de método para a educação em dança, mas que foi concebido bastante especificamente para seu momento, e dentro da tradição da dança russa. Ainda que alguns manuais venham de semelhantes propostas ligadas à ideia de dança clássica, seus diferentes backgrounds criam mudanças mesmo em elementos comuns da técnica - por exemplo, o posicionamento dos 
pés no passé, o quanto as pernas se cruzam quando em terceira posição, o como o corpo deve se organizar e quais músculos devem ser dominantes durante piruetas, e assim por diante.

As sistematizações e a preocupação com detalhes mostram uma consideração pela necessidade de padronização de alguns processos de treinamento e realização, garantindo a continuidade de uma tradição e de um estilo específicos, bem como das formas como eles são recebidos por seus públicos. É desse modo que a relação com os públicos aparece nessa forma de escrita. Essa ideia de determinar uma execução apropriada para a dança está presente no todo dos exemplos de Manuais. O An Elementary Treatise Upon the Theory and Practice of the Art of Dancing, de Carlo Blasis (1820), por exemplo, se aventura profundamente na prescrição de como o bailarino deve realizar a dança, se comportar, e mesmo, em alguns aspectos, viver.

Isso revela que, com relação ao entendimento da comunicação da dança por essa forma de escrita, o que se encontra é de natureza prescritiva. Os autores estão, de certa forma, dizendo o que os públicos desejam e esperam da dança, o que deve ser realizado, e a maneira apropriada de fazê-lo. Assim, as possibilidades de comunicação são ao mesmo tempo limitadas, posto que pré-determinadas, mas também garantidas e estabelecidas, posto que os autores partem de uma experiência de trabalho dentro das tradições que discutem, e, considerando o entendimento que têm das reações do público frente àquela tradição específica, eles organizam e apresentam a quem estuda e a quem ensina dança através daquele manual (já que os manuais servem sobretudo a propósitos educacionais) as habilidades necessárias para aquela específica comunicação e entendimento.

Essas considerações não são limitadas aos manuais de técnicas de dança clássica. Muitos dos pioneiros da dança moderna também trabalharam dentro desse tipo de sistemas fechados, tendo os seus sistemas sido apresentados em textos por eles próprios, por colaboradores seus, ou por especialistas que tenham estudado seus trabalhos. Doris Humphrey, Martha Graham e José Limón nomeando alguns poucos - possuem materiais que almejam ensinar suas técnicas - e seus sistemas - mesmo depois da morte desses artistas. Também, 
diversos criadores contemporâneos sentiram a necessidade de refletir sobre seus meios de trabalho, ensino e criação de danças, tendo produzido materiais escritos com essas considerações. Mais recentemente, no entanto, tais textos tentem a outras formas de abordagem: não mais a reflexão de fórmulas e ideias acerca do que seria a maneira apropriada de um movimento, como indicava-se nos manuais clássicos, mas também incluindo abordagens mais amplas, chegando mesmo a aventurarem-se pelo que aqui se chama de teoria da dança.

Dentro dessa abordagem mais atual, pode-se considerar, por exemplo, a série de livros e dvds da coreógrafa Anne Teresa de Keersmaeker em parceria com a pesquisadora de dança Bojana Cvejic (Keersmaeker, 2012), entitulada $A$ Choreographer's Score. No meio do caminho entre os manuais e a teoria, esses livros apresentam os arquivos dos processos criativos de algumas coreografias da Rosas (companhia fundada e dirigida por Keersmaeker), incluindo também entrevistas e comentários, além de instruções em vídeo que mostram como as obras devem ser dançadas. Os livros também incluem reflexões acerca da arte e do estilo da companhia belga, explicando suas intenções e as razões que guiaram seus processos. Por essa característica, ainda que haja instrução acerca de como se realizam as danças, esses não se tratam de manuais de estilo, já que não intencionam servir como um guia para um bailarino qualquer, numa situação qualquer, e servem mais como manuais daquelas coreografias das quais tratam especificamente.

Isso destaca o aspecto interdisciplinar dos manuais: sua integração com a educação. Como eles são construídos a partir das ideias de transmissão e aprendizado, eles podem ser vistos como ferramentas pedagógicas. Eles se amparam na forma escrita para que a informação do como dançar seja transmitida em uma forma facilmente multiplicável e reproduzível - e portanto bastante diferente da transmissão corpórea e verbal tradicional da dança. No entanto, seus conteúdos ainda podem variar bastante, desde a determinação do que deve ser feito e de como isso deve ser executado, até as reflexões do porquê as coisas precisam ser das formas como são propostas - um tópico que se associa mais à teoria da dança. 


\section{A Teoria da Dança: discussão, análise e síntese de sistemas}

Nos textos de Teoria da dança, o foco está na discussão, com a apresentação de múltiplos pontos de vista dos assuntos que se discutem, mesmo que, a certo ponto, também tenha existido nesse tipo de texto um tanto de prescrição. Um texto fundamental do período do início da formação da dança clássica como a conhecemos são as Cartas sobre a Dança, publicadas em 1760 por Jean-Georges Noverre (Monteiro, 2006). O coreógrafo e maître suíço pode ser considerado um dos primeiros a discutir como a dança comunica, e ainda que haja elementos prescritivos em suas cartas - sobretudo quando ele defende as reformas que considera necessárias ao balé - suas ideias são apresentadas em uma linha de pensamento e reflexão que é característica da teoria.

Se no trabalho de Blasis encontram-se sugestões pontualmente baseadas em preferências do público, Noverre discute a importância de que o bailarino entenda o trabalho - assim como de que o público entenda o bailarino advogando formas de interpretação que, ele considera, deveriam ser pesquisadas e criadas por artistas, baseadas não nas formas rígidas do balé de corte mas nas necessidades cênicas da comunicação daquela arte.

A teoria da dança também é muito útil quando coreógrafos e pesquisadores desejam explicar o como eles acreditam que as danças devam ser criadas. Foi esse o caso de Théophile Gaulthier, no início dos anos 1840, em seus artigos que explicavam algumas das razões do balé romântico. Também foi o caso de Michel Fokine (1980), que publicou dois textos, em 1914 e 1916, explicando os princípios do que ele chama de o novo balé, assim como as regras que ele acredita serem organizadoras da criação de danças.

Trabalhos mais recentes, como Dance Analysis: Theory and Practice, de Janet Adshead (1988) e Le Corps (1972) e De la Création Chorégraphique (2001), estes dois do francês Michel Bernard, se aventuram na apresentação dos sistemas de comunicação que se apresentam num evento de dança. Esses sistemas discretos organizam as possibilidades de criação e entendimento de obras de dança, e ao 
discutirem tais sistemas, os autores tentam se aproximar do entendimento da comunicação da dança enquanto linguagem.

Next Week Swan Lake: Reflections on Dance And Dances, de Selma Jeanne Cohen (1982), também articula comentários acerca de sistemas de dança, questionando o que o público pode entender a partir de uma obra de dança. A relação entre artistas e públicos é constantemente debatida, enquanto se avança acerca do entendimento da comunicação da dança, tanto enquanto possibilidade (teoricamente) como através de exemplos. É notável o exemplo de Cohen tratando da Fada Açucarada, do balé O Quebra Nozes. Quando ela questiona o que é uma Fada Açucarada e como ela seria reconhecida por alguém na rua, a autora inicia uma discussão acerca da comunicação do balé como dependente do libreto, entre outros temas. Nesse ponto, Cohen coloca em perspectiva alguns dos sistemas próprios ao balé clássico, referindo-se à sua tradição de background narrativo e intenção de contação de histórias.

Isso cria uma associação interdisciplinar entre a dança e a literatura. Historiadores, como Paul Bourcier (1978) e Jack Anderson (1981), consideram a narratividade como a principal separação entre as danças sociais que eram apresentadas nas cortes européias e as primeiras formas de balé, como o Ballet Comique de la Reine (1581, de Balthasar de Beaujoyeux). As danças de corte eram apresentadas em situações sociais, que, portanto, pressupunham participação, enquanto os balés de corte, mesmo que ainda apresentados como parte do entretenimento de festas, supunham uma distinção clara entre aqueles que dançavam e aqueles que assistiam à dança. Essa separação foi forçada pela ideia de se tratar a dança como uma forma de narrativa, que requeria uma preparação específica e ensaios, assim dando à dança o seu elemento cênico, se mostrando como uma referência maior para o entendimento de como a dança pode articular com outras formas artísticas. No entanto, deve-se manter em mente que esses elementos e relações são produtos diretos de seus tempos e estética, devendo, portanto, ser considerados também pela perspectiva histórica. 


\section{A História da Dança: os eventos e sua relevância}

Ainda que os primeiros manuais de dança tenham servido como uma forma de registro da história da dança - e de algumas danças em específico eventualmente os pesquisadores demonstram em suas publicações uma necessidade de se dirigirem mais especificamente à história. Desde a publicação do General History of Sacred and Profane Dances de Jacques Bonnet em 1724, as metodologias dos historiadores de dança têm variado bastante. Uma das principais mudanças é que as primeiras Histórias se apresentavam basicamente como recontos pessoais dos acontecimentos, baseados na memória e na transmissão entre indivíduos. Paralelamente à pertinência desses registros pessoais, a consideração da importância do uso de outras fontes primárias e documentais vai aparecendo, sendo hoje um dos aspectos mais relevantes na discussão dos trabalhos de história.

As histórias da dança trabalham intimamente com essa relação da tradição da transmissão oral, e também com o arquivamento e a documentação. Enquanto a documentação se foca em fontes históricas, no momento da investigação histórica - assim como no momento da escrita dos resultados dessa investigação - entra em jogo a autoria e a pessoalidade do autor. Aparece então a noção da história como entidade fictiva, que se constrói a partir de determinados acessos e apresentações (Rancière, 2000), ou seja: não há neutralidade absoluta ou imparcialidade possíveis, e o autor está presente nas decisões da metodologia da pesquisa, e na forma como os materiais encontrados são usados, discutidos, e apresentados, já que as múltiplas fontes geram múltiplas possibilidades de abordagem e apresentação.

Não é fácil encontrar, nem analisar, as múltiplas fontes que existem acerca de um dado período, de uma companhia, de uma escola, de um bailarino, de um coreógrafo, de um teatro, e assim por diante; e por esse motivo, existe um grande número de textos de história que preferem limitar seu escopo. Fixando a pesquisa em um indivíduo, companhia ou período, o pesquisador passa a dispor de mais 
tempo de pesquisa, e mais espaço de desenvolvimento, para um texto mais aprofundado em seu assunto. Também, isso responde pelo menor número de livros de História Geral, entre os quais podemos citar o já mencionado Histoire de la Danse en Occident, de Paul Bourcier (1978), também Dance, de Jack Anderson (1981), e Ballet and Modern Dance, de Susan Au (2002) - todos estes sendo exemplos da abordagem sucessiva dos estilos e formas de dança no tempo, com a discussão de sua relevância no contexto em que apareceram, assim destacando a continuidade e as mudanças dessa forma artística.

O livro de Jennifer Homans (2010), Apollo's Angels: A History of Ballet, exemplifica muito do que pode ser visto em outros exemplos de textos de história da dança. Como a principal proposta desse tipo de obra é a transmissão de informação, a maior parte daquilo que poderia ser tomado como opinião pessoal é apresentado por sua relação com fatos e eventos. Em relação aos sistemas de comunicação, esse tipo de material se preocupa com mostrar as formas como os sistemas se alteram ao longo do tempo, mais do que com analisar os sistemas em questão. Há um foco notável na relação entre artistas e públicos, e, ainda mais, entre artistas e seus contextos (sejam sociais, políticos, econômicos ou estéticos). Usualmente, o objetivo é de expandir o conhecimento acerca da dança em seu tempo, e apresentar o que se entendia através daquela forma de comunicação naquele contexto.

Apollo's Angels foi especialmente discutido não pela extensa pesquisa de Homans fez (abrangendo, e em riqueza de detalhes, períodos que comumente foram deixados de lado em outras das obras já mencionadas), mas sobretudo por seu epílogo, que, conforme seu título apresenta, propõe que 'The masters are dead and gone'. Esse epílogo incitou uma onda de respostas e mesmo edição de novos livros para questionar essa asserção e a consideração que ali é apresentada de um possível fim do balé. Sobre esse aspecto específico, enquanto a parte histórica de seu livro, ao oferecer dados e referências, tenta expandir o conhecimento que o leitor tem dos eventos do passado, no epílogo o foco passa para um nível de interpretação dos dados coletados, que, de certa forma, pode sugestionar o leitor 
a um entendimento (ao tentar convencê-lo), um procedimento que também é frequentemente associado à crítica de dança.

\section{A Crítica de Dança: apreciação, divulgação e reflexão}

São muitos os exemplos de críticas de dança, frequentemente compilados em obras antológicas de um autor ou de um grupo de autores ${ }^{3}$. Também há uma quantidade considerável de textos acerca do trabalho e da função da crítica textos de opiniões bastante divergentes, é importante mencionar. O papel do crítico de dança tem sido questionado, investigado, exaltado, e rejeitado ${ }^{4}$. A crítica de dança foi entendida como forma educativa, como informação geral, como opinião pessoal de gosto e preferência, e múltiplas outras possibilidades entre essas.

Uma separação fundamental nos textos de crítica pode ser proposta entre a crítica jornalística e a crítica acadêmica (Han, 2015). A crítica jornalística ocupa atualmente um papel fundamentalmente econômico com relação à dança, despertando interesse do público em produções, eventualmente levando-o a se interessar e considerar assistir às apresentações, assim fazendo com que as obras discutidas sejam conhecidas. Quando há a intenção da publicidade, normalmente os textos vão apresentar informações fundamentais de serviço - o como, onde e os preços das apresentações -, e, também dentro desse propósito, os textos desse tipo de crítica costumam ser feitos antes das apresentações (ou tão cedo quanto possível), assim se baseando também em ensaios, entrevistas e préestreias, para que a publicação possa chegar ao público com tempo hábil de atender sua função de divulgação. Esse formato da crítica reflete usos contemporâneos da mídia, sobretudo impressa, e não pode ser pontuado como

\footnotetext{
3 Exemplos notáveis desse tipo de proposta podem ser encontrados em Beaumont, 1950; Denby, 1969; Anderson, 1987; SiegeL, 1992; Netrovski, 2004; Pereira, 2009; e Perron, 2013.

${ }^{4}$ Conforme Guest, 1962; Sorell,1965; Denby, 1979; Farndale, 1990; Burnside, 1991; Acoacella, 1992; Ferreira, 1995; Copeland, 1993; Bernard 2011; e Rochelle, 2016 - nomeando apenas algumas das muitas referências possíveis.
} 
uma constante na história desse tipo de texto, que já encontrou, inclusive dentro do jornalismo opinativo, amplo espaço para a reflexão e o debate acerca da arte (Ballerini, 2015).

Quando existente, essa intersecção entre o campo econômico e publicitário, aplicada às artes da cena, pode refletir uma importância do feedback editorial como maior do que o texto escrito, e, portanto, maior do que a própria obra discutida, e o espaço do jornal pode ser vendido como commodity que capta possíveis públicos. Se há múltiplas opções de apresentações de dança a assistir, a opinião do crítico pode se tornar influente na decisão de qual será a escolhida, e também em como essa obra será entendida.

De um outro lado, temos a crítica acadêmica, presente nas universidades, nas revistas e periódicos especializados, e focada num estudo mais aprofundado e estruturado das obras, portanto sendo necessariamente posterior a elas. Esse tipo de crítica é criado como forma de consideração da obra, podendo se propor a elucidar a obra para o público ou para a comunidade acadêmica, discutindo seus aspectos, qualidades da performance, a relevância daquela dança e assim por diante (Carroll, 1987), propondo outras formas de debate e discussão sobre a arte da dança. Ainda que os nomes aqui propostos como separação possam sugerir que a divisão proposta se baseia na mídia e no formato de publicação do texto, ela considera muito mais as intenções dos autores como seu elemento determinante - ainda que essas intenções sejam de fato frequentemente ligadas de muitas maneiras a suas mídias específicas.

Sally Banes (1994) considera quatro diferentes operações que um crítico realiza em seu trabalho: descrição, contextualização, avaliação e interpretação. Essas operações podem se relacionar em múltiplas formas aos aspectos que aqui são discutidos. A descrição é o método que o crítico usa para apresentar os sistemas empregados naquela comunicação. Mesmo que não sejam discutidos, eles são descritos, assim dando ao leitor uma forma de acesso à obra. Se o leitor assistiu à obra, ele pode ser capaz de lembrar, através da descrição, pontos principais que o crítico considera relevantes para a análise proposta. Se o leitor não assistiu à obra, a descrição pode ajudá-lo a ter uma ideia, mesmo que parcial, 
dela. Ao contextualizar e avaliar uma obra, o crítico coloca esses sistemas em relação com seu tempo, estabelecendo a aproximação entre os artistas e os públicos - e ele mesmo, enquanto membro do público - e apresentando uma experiência de recepção que pode diferir da experiência de outra pessoa, mas continua sendo uma experiência, real, e, na crítica, tornada pública, partilhada.

No entanto, ao interpretar uma obra, o crítico está sempre em uma situação difícil. De um lado, sua opinião pode ser exigida (por alguns editores) e desejada (por alguns leitores); por outro lado, ao oferecer uma opinião interpretativa, o crítico pode interferir com as opiniões dos leitores, limitando-as, predeterminando-as (ver em Denby, 1969, a discussão dos muitos pontos de vista acerca da relação entre o crítico e o entendimento do público). Esse risco foi explorado profundamente em formas de crítica que focam na avaliação da obra e que oferecem opiniões e preferências pessoais como forma de validação ou questionamento das obras que consideram. A crítica avaliativa, extremamente popular desde o balé romântico, e principalmente voltada para a apreciação, sofreu, a certo momento, uma grande resistência por parte do público leitor, e, historicamente, observam-se muitas alterações no foco dessas quatro operações.

De acordo com Banes (1994) cada texto de crítica pode misturar as dosagens dessas quatro operações, mas observamos que alguns autores mostram preferências em suas escolhas, por exemplo, nas críticas interpretativas da New York School of Criticism (Theodores, 1996), que apresenta a experiência individual da dança como forma valiosa e interessante de crítica. O aspecto mais relevante desse sistema de quatro operações é sua múltipla possibilidade de dosagens, no sentido de criar combinações únicas, ao mesmo tempo que, paradoxalmente, essas combinações podem ser capazes de emular características das outras categorias de textos aqui discutidas, criando críticas de orientação histórica, ou que destacam a assertividade dos manuais, ou a característica investigativa da teoria. Talvez por essa possibilidade de emprestar das outras formas de escrita a crítica tenha sido pontuada por Carter (1976) como o nível primeiro da escrita acerca da dança, expressão que a autora traduz a partir de um entendimento de que dentre as múltiplas possibilidades de se escrever sobre dança, como as aqui 
apresentadas, a crítica é aquela que mais se aproxima de fato da apresentação da dança.

Comparativo dos Sistemas de Comunicação dos Textos sobre Dança

A ideia de que o texto e o estudo da dança possam invadir o espaço pessoal da relação entre artistas e públicos não é rara nem novidade, tampouco é ela uma ideia simples, e pode ser considerada a partir da perspectiva de cada uma das categorias aqui apresentadas. Enquanto manuais frequentemente têm uma característica assertiva que lida com a dança através de sistemas fechados de comunicação, isso se faz, como mencionado, na intenção de preservar e disseminar os sistemas específicos de um criador, de uma escola, de uma tradição em dança. Essa ideia de preservação considera as visões particulares das relações que estes indivíduos ou instituições desejam criar com seus públicos, e ainda que assim se limitem essas relações, esse procedimento intenciona garantir sua manutenção e preservação enquanto possibilidade comunicativa.

Esse processo não se apresenta nas ideias da teoria da dança, que tem um caráter investigativo ao pesquisar os sistemas que organizam a comunicação da dança. Essa intenção se percebe na discussão das relações entre artistas e públicos, e na necessidade de questionamentos estéticos baseados nessas relações. As possibilidades de comunicação da dança são tidas por essa forma como múltiplas e amplas, e consideradas enquanto potenciais, sendo analisadas por exemplos de situações de criação e apresentação de obras de dança.

Quando esses exemplos são considerados, sobremaneira, por sua inserção em seu tempo, vemos a característica contextual das histórias. A escrita da história da dança pode apresentar relações estruturadas de entendimento, mas unicamente tanto quanto elas venham da análise de dados específicos que revelem informações pontuais dos momentos discutidos. Como o acesso à informação histórica é normalmente determinado pelo poder institucional do 
arquivo (Derrida, 1995) e pelo esquecimento e pelo aspecto performativo da memória, as análises que resultam desses dados são indicativas de muito mais do que apenas fatos e eventos (Rochelle, 2018). Não obstante, pelo uso de múltiplas fontes frente a seus objetos, historiadores tentam contextualizar as possibilidades de comunicação da dança, enfatizando suas mudanças e continuidades, assim permitindo um entendimento dos múltiplos aspectos das relações entre artistas e públicos.

Focando na experiência da obra de dança, o caráter fenomenológico da crítica mostra uma recepção pontual - a do crítico - em relação aos trabalhos que ele discute. Assim, é criada uma forma de pessoalidade, informada pelo trabalho e suas escolhas artísticas, que é contextualizada pelo conhecimento do crítico acerca dessa forma artística. Enquanto essa experiência pessoal é publicizada e partilhada, o background que organiza aquela experiência específica é colocado em evidência, da mesmo forma que o background de cada obra organiza seus sistemas de comunicação, parcialmente apresentados e descritos pelo crítico em seus textos.

Vê-se que as múltiplas possibilidades de escritas sobre a dança são frequentemente interligadas interdisciplinarmente aos campos que as alimentam, quanto a seus objetivos, mídia, públicos e afiliações autorais. Mais, ainda, observase que o elemento que conecta essas múltiplas fontes, quando elas são aplicadas à dança, é a relevância da comunicação da dança: o entendimento das criações de dança, e a transmissão e discussão desse entendimento, que se reflete tanto nas formas de escrita quanto nos campos do saber que ajudam a alimentá-las, conforme previamente discutido.

Ainda que articulem a comunicação da dança em modos diferentes, todos esses diferentes tipos de escrita fundamentalmente discutem esse processo, intimamente relacionado à possibilidade de entendimento de eventos de dança. Tem-se a dança enquanto forma artística que se completa no momento da apresentação, ao contato com o público, e a ideia de um sistema, intencionado para a apresentação, estabelecido para criar entendimento. Ao discutir a comunicação da dança, os escritos de dança oferecem percepções acerca das 
possibilidades de estruturação dos sistemas que organizam essa comunicação. Eles apresentam, de seus distintos modos, formas de entendimento daquilo que acontece no momento da apresentação e que permite que a dança comunique algo a alguém.

Considerando o que se escreveria sobre a dança, e por quê isso seria feito, assim como não há apenas uma forma de escrita sobre a dança, não há apenas uma resposta a essas questões. Poder-se-ia sugerir que se escreve sobre a dança pelo mesmo motivo que se assiste à dança: porque ela interessa, move, porque ela se comunica com alguém e esse alguém deseja se comunicar de volta (com ela) e adiante (passando-a para outros). Pode-se apresentar os tipos de textos sobre a dança, suas particularidades, e sua relevância. Pode-se apresentar a relação íntima entre a palavra escrita e o registro da história. Todas essas, possibilidades comunicativas, que reforçam a prerrogativa da dança enquanto sistema de comunicação. A necessidade e o desejo dessa comunicação, são, afinal, o motivo principal, tanto dos textos sobre a dança, como deste texto, sobre os textos sobre a dança.

\section{Referências}

ACOCELLA, J. How Critics Work. Dance Ink. Vol. 3, N. 2. p. 8-10, Summer 1992.

ADSHEAD, J. Describing components of the dance. In: ADSHEAD, J. (Ed.). Dance Analysis: Theory and Practice. London: Dance Books, 1988.

ANDERSON, J. Choreography Observed. Iowa City: University of Iowa Press, 1987.

ANDERSON, J.. Dance. New York: Dance Horizons,1981.

ARBEAU, T. Orchésographie: traité en forme de dialogue par lequel toutes personnes peuvent facilement apprendre et pratiquer l'honneste exercice des danses. Langres: Ichan, 1589.

AU, S. Ballet and Modern Dance. Revised and expanded edition. London: Thames \& Hudson Ltd, 2002.

BALLERINI, F. Jornalismo Cultural no Século 21. São Paulo: Summus, 2015. 
BANES, S. Writing dancing in the age of postmodernism. Middletown: Wesleyan University Press, 1994.

BARTHES, R. O Grão da voz. Rio de Janeiro: Francisco Alves, 1995.

BARTHES, R. O Rumor da Lingua. São Paulo: Martins Fontes, 2004.

BARTHES, R. Rhétorique de l'image. Communications, no 4, p. 40-51, 1964.

BEAUMONT, C. (org.). Dancers and Critics. Edinburgh: A. and C. Black, 1950.

BERNARD, M. De la création chorégraphique. Paris: Centre National de la Danse, 2001.

BERNARD, M. Généalogie du Jugement Artistique. Paris: Bauchesne, 2011.

BERNARD, M. Le Corps. Paris: Éditions du Seuil, 1972.

BLASIS, C. An Elementary Treatise Upon the Theory and Practice of the Art of Dancing. Dover: Dover Publ., 1968.

BONNET, J.; BOURDELOT, P. Histoire générale de la danse sacrée et profane.

Paris: D'Houry, 1724.

BOURCIER, P. Historie de la Danse en Occident. Paris: Éditions du Seuil, 1978.

BURNSIDE, F. In Defence of Dance Criticism. Dance Theatre Journal. Vol. 9, N. 1. p. 22, Summer 1991.

CARROLL, N. 1987. Trois propositions pour une critique de la danse contemporaine. In: LEFEBVRE, M. (Ed.). La danse au défi. Montréal: Éditions Parachute, 1987.

CARTER, C. Some Notes on Aesthetics and Dance Criticism. Dance Scope, V. 10, N. 2, S/S, p.35-39, 1976.

CERBINO, B. Dança e memória: usos que o presente faz do passado. In: BOGEA, I. (Org.). Primeira Estação: Ensaios sobre a São Paulo Companhia de Dança. São Paulo: Imprensa Oficial do Estado de São Paulo: São Paulo Companhia de Dança, 2009.

COHEN, S. J. 1982. Next week, Swan Lake: reflections on dance and dances. Middletown: Wesleyan University Press, 1982.

COPELAND, R. Dance criticism and the descriptive BIAS. Dance Theatre Journal. Vol. 10, N. 3. p. 26-32, S/S 1993. 
CROCE, A. et al. Writing about the Dance: a symposium. Ballet Review. Vol. VII, N. 4. p.108-124,1978.

DENBY, E. A Conversation with Edwin Denby II. Ballet Review. Vol. 2, N. 6. p. 32-45, 1969.

DENBY, E. Reminiscences of a Dance Critic. Performing Arts Journal, Vol. 4, No. 1/2, p. 52-61, May, 1979.

DERRIDA, J. Mal d'archive. Paris: Galilée, 1995.

EKSTEINS, M. Rites of Spring: The Great War and the Birth of Modern Age. New York: Houghton Mifflin Company, 2000.

FARNDALE, N. Against Dance Criticism. Dance Theatre Journal. Vol. 8, N. 3. p. 1618, Autumn 1990.

FERREIRA, V. S. Do lugar da crítica. Análise Social. Vol. 30, No. 134, pp. 977-1022, 1995.

FOKINE, M. Theories on the Art of Ballet. In: STEINBERD, C. (Ed.). The Dance Anthology. New York: Plume, 1980.

GUEST, I. Ballet Criticism: the historian's view. Ballet Annual. N. 16 . p. 63-71. 1962. HAN, J. Creuser la Distance dans le Temps des Revues. In: WALLON, E. (Dir.) Scènes de la Critique. Paris: Actes Sud, 2015.

HOMANS, J. Apollos's Angels, a history of ballet. New York: Random House, 2010.

JAKOBSON, R. Selected Writings, Vol II: Word and Language. Paris: Mouton, 1971.

KEERSMAEKER, A. T.; CVJIC, B. A Choreographer's Score. Brussels: Mercatorfonds

- Rosas, 2012.

LAUNAY, I. À L'écoute du souvenir. Repères, Cahier de Danse, 28: 8-10, 2011.

LAYSON, J.Dance History Source Materials. In: CARTER, A (ed.) Routledge Dance Studies Reader. London: Routledge, 1998.

MONTEIRO, M. Noverre: Cartas sobre a dança. 1a reimpressão. São Paulo: Editora da Universidade de São Paulo: FAPESP, 2006.

NAVAS, C. Entrevistar e Escrever: procedimentos para palavras encarnadas de dança. Revista Brasileira de Estudos da Presença, 5 (3): 559-76, 2015.

NESTROVSKI, A. (Org.). Em Branco e Preto: Artes brasileiras na Folha, 1990-2003. São Paulo: Publifolha, 2004. 
PEREIRA, R. (Org.). Ao lado da crítica: 10 anos de crítica de dança: 1999-2009. 2 v. Rio de Janeiro: Funarte, 2009.

PERRON, W. Through the eyes of a dancer. Selected writings. Middletown: Wesleyan University Press, 2013.

RANCIÈRE, J. Le Partage du sensible. Paris: La Fabrique-Éditions, 2000.

ROCHELLE, H. A Crítica como Metodologia e Análise da Recepção na Dança. (Tese) Doutorado em Artes da Cena. Unicamp, Campinas, 2017.

ROCHELLE, H. Além da Opinião: três possíveis definições da crítica de dança. Sala Preta, v. 16, n. 2, 2016.

ROCHELLE, H. Elementos da Dança como Linguagem: "no Singular" de Henrique Rodovalho. (Dissertação) Mestrado em Artes da Cena. Unicamp, Campinas, 2013.

ROCHELLE, H. Memória e Registro dos Arquivos do Corpo. Revista Cena, Porto Alegre, n. 25, p. 67-74, 2018.

ROCHELLE, H. Rethinking Dance Theory Through Semiotics, Studies About Languages, Kaunas, Lituania, No 26, 2015, p. 110 - 125.

SIEGEL, M. B. An Audience of One. Dance Ink. Vol. 3, N. 2. p. 26-27, Summer 1992.

SORELL, W. To Be a Critic. Dance Scope. Vol. 1, N. 1. p. 1-9, Winter 1965.

THEODORES, D. First We Take Manhattan: four american women and the New York school of dance criticism. Amsterdam: Hardwood Academic Publishers, 1996.

VAGANOVA, A. Basic principles of classical ballet. Chelmsford: Courier Corporation, 1969.

Recebido em: 12/04/2020

Aprovado em: 16/06/2020 